\title{
Breast cancer and hormone-replacement therapy in the Million Women Study
}

\section{Summary}

Background Current use of hormone-replacement therapy (HRT) increases the incidence of breast cancer. The Million Women Study was set up to investigate the effects of specific types of HRT on incident and fatal breast cancer.

Methods 1084110 UK women aged 50-64 years were recruited into the Million Women Study between 1996 and 2001, provided information about their use of HRT and other personal details, and were followed up for cancer incidence and death.

Findings Half the women had used HRT; 9364 incident invasive breast cancers and 637 breast cancer deaths were registered after an average of 2.6 and 4.1 years of follow-up, respectively. Current users of HRT at recruitment were more likely than never users to develop breast cancer (adjusted relative risk 1.66 [95\% Cl 1.58-1.75], p<0.0001) and die from it (1.22 [1.00-1.48], $p=0.05)$. Past users of HRT were, however, not at an increased risk of incident or fatal disease (1.01 [0.94-1.09] and 1.05 [0.82-1.34], respectively). Incidence was significantly increased for current users of preparations containing oestrogen only (1.30 [1.21-1.40], $\mathrm{p}<0.0001)$, oestrogen-progestagen $(2.00 \quad$ [1.88-2.12], $\mathrm{p}<0.0001)$, and tibolone (1.45 [1.25-1.68], $\mathrm{p}<0.0001)$, but the magnitude of the associated risk was substantially greater for oestrogen-progestagen than for other types of HRT $(p<0.0001)$. Results varied little between specific oestrogens and progestagens or their doses; or between continuous and sequential regimens. The relative risks were significantly increased separately for oral, transdermal, and implanted oestrogen-only formulations (1.32 [1.21-1.45]; 1.24 [1.11-1.39]; and 1.65 [1.26-2.16], respectively; all $\mathrm{p}<0.0001)$. In current users of each type of HRT the risk of breast cancer increased with increasing total duration of use. 10 years' use of HRT is estimated to result in five $195 \% \mathrm{Cl}$ 3-7) additional breast cancers per 1000 users of oestrogenonly preparations and 19 (15-23) additional cancers per 1000 users of oestrogen-progestagen combinations. Use of HRT by women aged 50-64 years in the UK over the past decade has resulted in an estimated 20000 extra breast cancers, 15000 associated with oestrogen-progestagen; the extra deaths cannot yet be reliably estimated.

Interpretation Current use of HRT is associated with an increased risk of incident and fatal breast cancer; the effect is substantially greater for oestrogen-progestagen combinations than for other types of HRT.

Lancet 2003; 362: 419-27

See Commentary page 414

Correspondence to: Prof Valerie Beral, Cancer Research UK Epidemiology Unit, Gibson Building, Radcliffe Infirmary, Woodstock Road, Oxford OX2 6HE, UK

\section{Introduction}

Results from randomised controlled trials and from observational studies show that current and recent use of hormone-replacement therapy (HRT) increases the risk of breast cancer. ${ }^{1-4}$ However, the effect of HRT on mortality from breast cancer is unclear ${ }^{1-5}$ and use of HRT preparations containing oestrogen-progestagen combinations may be associated with a greater risk of breast cancer than preparations containing oestrogen alone..$^{6-10}$ The Million Women Study, a cohort study of a quarter of British women aged 50-64 years, was set up chiefly to investigate the relation between various patterns of use of HRT and breast cancer incidence and mortality. ${ }^{11}$

\section{Methods \\ Data collection and definitions}

The National Health Service Breast Screening Programme (NHSBSP) invites all women in the UK aged 50-64 years for routine screening once every 3 years. From May, 1996, to March, 2001, the NHS breastscreening centres participating in the Million Women Study included the study questionnaire together with their letter of invitation for routine mammography. ${ }^{11}$ This letter is generally posted 2-6 weeks before the woman's screening appointment. The questionnaire is returned before women are screened and can be viewed at http://www.millionwomenstudy.org. It contains questions about sociodemographic and other personal factors, including information about use of HRT and menstrual history. The study design, characteristics of the cohort, and patterns of use of HRT have been described elsewhere. ${ }^{11-13}$ For a sample of the study population validation studies were done, comparing self-reported data with information in family physicians' records. ${ }^{14}$

Women were classified according to their reported use of HRT, menopausal status, and other relevant factors at recruitment-ie, at baseline. Information collected about use of HRT at baseline included: ever use; current use; age at first and last use; total duration of use; and the name of the proprietary preparation used most recently and duration of its use. The specific constituents and formulations of each proprietary preparation of HRT was obtained from the British National Formulary. ${ }^{15}$ This information was used to classify the type of preparation used as: oestrogen only; oestrogen-progestagen combination; tibolone, which contains no oestrogen or progestagen; other preparations, including progestagen only, vaginal and other local treatments, and combinations of the above types; or unknown. Users of oestrogen-only preparations were further subdivided according to the specific oestrogen constituent of the HRT (equine oestrogen or oestradiol), its dose, and whether it was administered as an oral, transdermal, or implanted formulation. Users of combined HRT were separated into subgroups by the specific progestagen constituent (medroxyprogesterone acetate, norethis- 
terone, or norgestrel or levonorgestrel) and whether the progestagen was administered as a sequential or continuous regimen.

Menopausal status at recruitment could be defined for most women by their reported menstrual history-ie, premenopausal, perimenopausal, and postmenopausal women were, respectively, those reporting that they still had regular menstrual periods, that their periods were irregular, and that their periods had stopped naturally or after bilateral oophorectomy. Menopausal status can, however, be masked by a hysterectomy or by use of HRT before the natural menopause, and the following conventions were adopted to define menopausal status at recruitment in these circumstances: at age 53 years or older, women were classified as postmenopausal (since $96 \%$ of the study population aged $\geqslant 53$ years who had not had a hysterectomy or used HRT were postmenopausal); at age 50-52 years such women were classified as having an unknown menopausal status (since, at that age, the study population was fairly equally divided between premenopausal, perimenopausal, and postmenopausal women). For women thus classified as postmenopausal, the time since menopause was assumed to be similar to that of women of a similar age who had a natural menopause-ie, less than 5 years for women aged 53-54 years at recruitment; 5-9 years for women aged 55-59 years; and 10 years or more for women aged 60 years or older. Sensitivity analyses were done to assess the robustness of these assumptions.

\section{Flagging and follow-up}

Study participants were flagged on the NHS Central Registers so that cancer registrations and deaths could be routinely notified to the investigators. The Central Registers provide information on the date of each such event and code the cancer site and cause of death according to the 10th revision of the International Classification of Diseases (ICD). ${ }^{16}$ The endpoints included in these analyses are first diagnosis of invasive breast cancer (ICD C50) and deaths attributed to breast cancer (ICD C50). Women with any cancer registered before recruitment were excluded from the analyses, except if they had a previous non-melanoma skin cancer, (ICD C44). Person-years were calculated from the date of recruitment to the date of cancer registration, death, or the last date of follow-up. Notification of death is more up to date than notification of cancer registration, and the last date of follow-up was Dec 31, 2002, for analyses of mortality, and Dec 31, 2001, for analyses relating to cancer incidence (except for the areas covered by the southwest, northwest, and Trent cancer registries, for which Dec 31, 2000, was the last date of follow-up).

\section{Statistical analyses}

Relative risks for breast cancer and death from breast cancer were estimated with Cox's regression models, in which the underlying time variable was defined as the time from date of recruitment to date of breast cancer diagnosis, death from breast cancer, or censoring. Analyses were stratified by age at recruitment (50-52, $53-55,56-59,60-62$, and 63-64 years) and adjusted for time since menopause ( $<5,5-9$, and $\geqslant 10$ years); childbearing history (nulliparous; and parous women were cross classified by parity $[<3$ or $\geqslant 3]$ and age at first birth $[<20,20-29, \geqslant 30$ years]); a first-degree relative with a history of breast cancer (yes or no), body-mass index $\left(<25\right.$ and $\left.\geqslant 25 \mathrm{~kg} / \mathrm{m}^{2}\right)$; nine regions (according to areas covered by nine cancer registries); and five categories of deprivation index (with the Townsend score, based on car and home ownership, unemployment, and overcrowding in the area of residence ${ }^{12}$ ). When only two groups are compared, the relative risk of breast cancer and the associated CI are presented. However, when more than two groups are compared, variances are estimated by treating the relative risks as floating absolute risks. ${ }^{1,17}$ Use of floating methods does not alter the estimates of relative risk, but yields floated SE and floated CI that enable valid comparisons to be made between any two exposure groups, even if neither is the baseline group. All analyses were done with the STATA computing package (version 7.0 ).

The cumulative number of incident cancers diagnosed in 1000 women up to age 65 years was calculated by applying the estimates of relative risk, according to total duration of use of HRT, to age-specific cancer incidence rates typical for women in developed countries. ${ }^{1,18}$ The number of incident breast cancers attributable to the use of HRT in the UK was calculated by applying estimates of relative risk and information on the prevalence of use of HRT in the general UK population over the past decade ${ }^{5,14,19}$ to breast cancer incidence in UK women aged 50-64 years. ${ }^{20}$

\section{Role of the funding source}

The sponsors of the study had no role in the study design, data collection, data analysis, data interpretation, or writing of the report.

\section{Results}

These results are based on the follow-up of 1084110 women recruited between 1996 and 2001, who were flagged on the NHS Central Registers and who had not been registered as having had cancer before they joined the Million Women Study. The average age of the women at recruitment was 55.9 years, and the average period of follow-up was 2.6 years for analyses of the cancer incidence and $4 \cdot 1$ years for analyses of mortality. During

\begin{tabular}{|c|c|c|c|c|}
\hline & $\begin{array}{l}\text { Women flagged on NHS } \\
\text { Central Registers ( } n \text { ) }\end{array}$ & $\begin{array}{l}\text { Ever users of HRT } \\
\text { (n [\%]) }\end{array}$ & $\begin{array}{l}\text { Incident breast } \\
\text { cancer }(n)\end{array}$ & $\begin{array}{l}\text { Breast cancer } \\
\text { deaths }(n)\end{array}$ \\
\hline \multicolumn{5}{|l|}{ Menopausal status at baseline } \\
\hline Premenopausal & 63153 & $6023(10 \%)$ & 645 & 26 \\
\hline Perimenopausal & 77833 & 11356 (15\%) & 597 & 38 \\
\hline Postmenopausal & 828923 & $436166(53 \%)$ & 7140 & 517 \\
\hline$<5$ years since menopause & 237639 & $127022(53 \%)$ & 1953 & 141 \\
\hline 5-9 years since menopause & 295168 & $175700(60 \%)$ & 2724 & 185 \\
\hline$\geqslant 10$ years since menopause & 296116 & $133444(45 \%)$ & 2463 & 191 \\
\hline Unknown & 114201 & 96627 (85\%) & 982 & 56 \\
\hline Age $50-52$ years and hysterectomy before menopause & 45968 & $30873(67 \%)$ & 380 & 33 \\
\hline Age $50-52$ years and HRT before menopause & 60606 & $60606(100 \%)$ & 544 & 18 \\
\hline Information on menopause missing & 7627 & $5143(67 \%)$ & 58 & 5 \\
\hline Total & 1084110 & $550172(50 \%)$ & 9364 & 637 \\
\hline
\end{tabular}

Table 1: Numbers of women flagged on the NHS Central Registers numbers (\%) who ever used HRT, and numbers of incident invasive and fatal breast cancers 


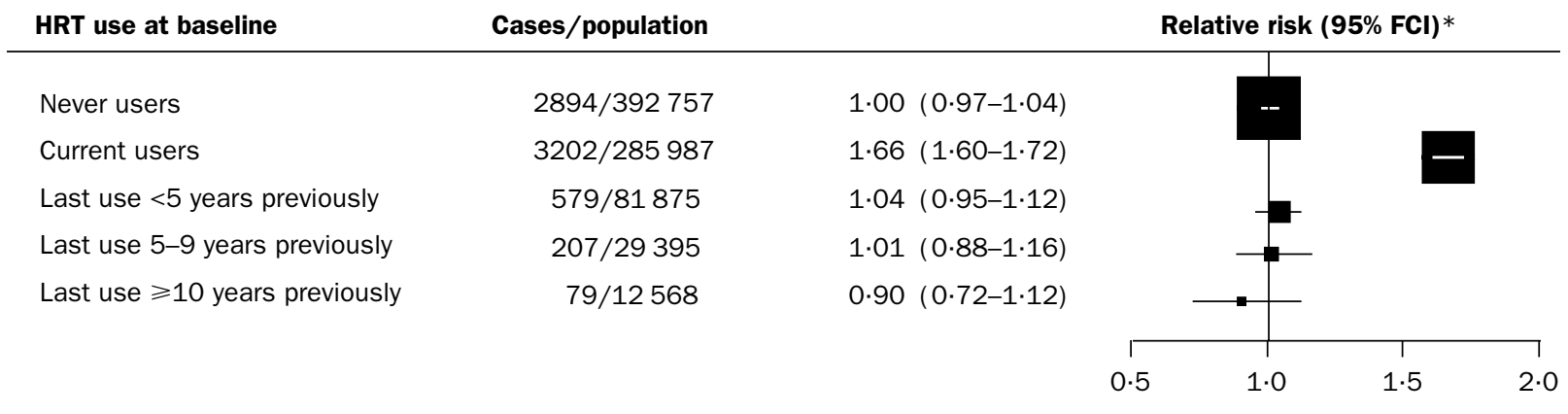

$\chi^{2}$ for heterogeneity between ever users $=161 \cdot 5, p<0 \cdot 0001$

Figure 1: Relative risk of incident invasive breast cancer in relation to recency of use of HRT

$\mathrm{FCl}=$ floated $\mathrm{Cl}$. *Relative to never users, stratified by age, time since menopause, parity and age at first birth, family history of breast cancer, body-mass index, region, and deprivation index.

the follow-up period, 9364 incident invasive breast cancers and 637 deaths from breast cancer were notified by the NHS Central Registers. The breast cancers were diagnosed on average 1.2 years after recruitment, and the median year of diagnosis was 1999. For the women who died from breast cancer, the average time between diagnosis and death was 1.7 years, the median year of death being 2001 .

Table 1 shows details of the study population, the number of incident invasive breast cancers and breast cancer deaths, and the proportion of ever users of HRT at baseline, by menopausal status. Overall, $50 \%$ of the study population had used HRT at some time, but the proportion of ever users varied substantially according to menopausal status at baseline-from $10-15 \%$ in premenopausal and perimenopausal women to $53 \%$ in postmenopausal. The relative risk of breast cancer also varied substantially according to menopausal status; for example, among never users of HRT the relative risk of invasive breast cancer was $0.75(95 \%$ CI $0.68-0.82)$ for perimenopausal and $0.63(0.58-0.68)$ for postmenopausal, compared with premenopausal women. To keep confounding by factors associated with the menopause to a minimum, the main analyses of the risk of breast cancer in relation to use of HRT were restricted to postmenopausal women with a defined time since menopause. Results of sensitivity analyses, examining the effect of stricter exclusion criteria, are given separately.

Among the 828923 postmenopausal women included in the main analyses, the risk of breast cancer was significantly higher among ever users than among never users of HRT at baseline (relative risk 1.43 [1.36-1.50], $\mathrm{p}<0 \cdot 0001)$. However, among ever users of HRT the relative risk of breast cancer was increased in current but not in past users at baseline $(1.66[1.58-1.75], \mathrm{p}<0.0001$; and $1.01[0.94-1 \cdot 09], p=0 \cdot 8$, respectively; heterogeneity $\mathrm{p}<0.0001)$. In past users, the risk of breast cancer did not differ significantly from that of never users of HRT, for use that ceased less than 5 years, 5-9 years, and 10 or more years previously (heterogeneity $p=0.5$, figure 1 ), although among women who ceased use of HRT in the previous year, the relative risk of breast cancer was slightly increased $(1 \cdot 14[1 \cdot 01-1 \cdot 28], \mathrm{p}=0 \cdot 03)$.

Most of the current users of HRT at baseline reported using preparations containing oestrogen only $(41 \%)$ or oestrogen-progestagen combinations $(50 \%) ; 6 \%$ reported using tibolone, $1 \%$ reported using other preparations, and the type of HRT used was unknown for $2 \%$. The relative risk of breast cancer was significantly raised for current users of oestrogen-only preparations $(1 \cdot 30$ [1.21-1.40], $\mathrm{p}<0.0001)$, oestrogen-progestagen combinations $(2 \cdot 00$ $[1 \cdot 88-2 \cdot 12], \mathrm{p}<0 \cdot 0001)$, and tibolone $(1 \cdot 45$ [1.25-1.68], $\mathrm{p}<0.0001)$. However, the magnitude of the relative risk of breast cancer varied significantly between these three HRT types $(\mathrm{p}<0 \cdot 0001)$ and was substantially greater in users of oestrogen-progestagen combinations than other preparations (figure 2). Included among users of other or unknown preparations were 618 current users of progestagen-only preparations $(2 \cdot 02[1 \cdot 05-3 \cdot 89], p=0 \cdot 04$, based on nine incident breast cancers) and 1196 current users of vaginal or other local HRT preparations $(0 \cdot 67$ [0.30-1.49], $p=0 \cdot 3$, based on six incident breast cancers). Compared with never users, the relative risk of breast cancer was $0.97(0.83-1.13)$ for past users of oestrogen-

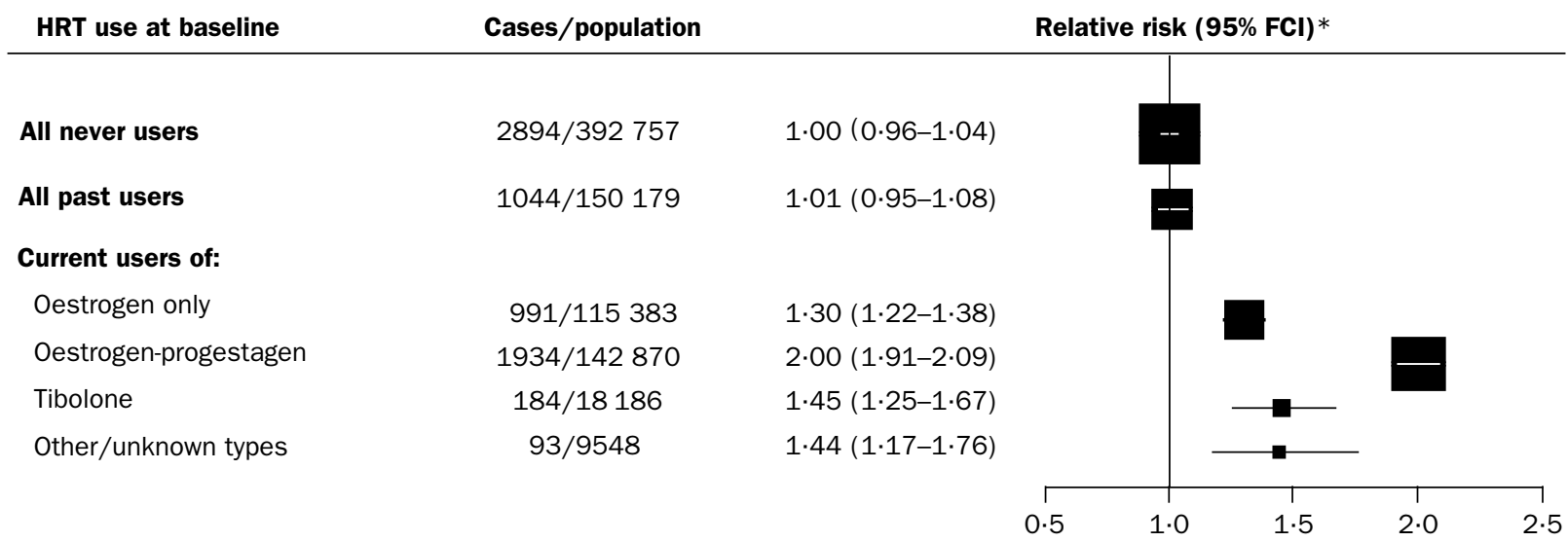

Figure 2: Relative risk of incident invasive breast cancer in relation to recency and type of HRT used

$\mathrm{FCl}=$ floated $\mathrm{Cl}$. *Relative to never users, stratified by age, time since menopause, parity and age at first birth, family history of breast cancer, body-mass index, region, and deprivation index. 


\section{Total duration of use of HRT by type of \\ HRT used at baseline}

$\begin{array}{lcc}\text { Never users of HRT } & & \\ \text { Past users of HRT } & & 1.00(0.96-1.04) \\ \text { <1 year } & 311 / 47606 & 0.94(0.84-1 \cdot 05) \\ 1-4 \text { years } & 384 / 55823 & 1.01(0.92-1 \cdot 12) \\ 5-9 \text { years } & 230 / 29614 & 1.14(1.00-1.30) \\ \geqslant 10 \text { years } & 80 / 11654 & 1.05(0.84-1.30)\end{array}$

\section{Current users of oestrogen-only HRT}

$\begin{array}{lc}<1 \text { year } & 25 / 4452 \\ 1-4 \text { years } & 251 / 29582 \\ 5-9 \text { years } & 416 / 47310 \\ \geqslant 10 \text { years } & 277 / 31862\end{array}$

$0.81(0.55-1 \cdot 20)$

$1 \cdot 25(1 \cdot 10-1 \cdot 41)$

$1.32(1 \cdot 20-1 \cdot 46)$

$1 \cdot 37(1 \cdot 22-1 \cdot 54)$

Current users of oestrogen-progestogen combinations

$\begin{array}{lcc}<1 \text { year } & 97 / 9771 & 1.45(1 \cdot 19-1 \cdot 78) \\ 1-4 \text { years } & 582 / 49240 & 1 \cdot 74(1 \cdot 60-1 \cdot 89) \\ 5-9 \text { years } & 850 / 56912 & 2 \cdot 17(2 \cdot 03-2 \cdot 33) \\ \geqslant 10 \text { years } & 362 / 23673 & 2.31(2 \cdot 08-2 \cdot 56)\end{array}$

\section{Current users of other/unknown HRT types}

$\begin{array}{lcc}<1 \text { year } & 19 / 1728 & 1.63(1.04-2.56) \\ 1-4 \text { years } & 83 / 8794 & 1.34(1.08-1.66) \\ 5-9 \text { years } & 102 / 10342 & 1.42(1.17-1 \cdot 72) \\ \geqslant 10 \text { years } & 59 / 4739 & 1.93(1.50-2.50)\end{array}$

Relative risk $(95 \% \mathrm{FCI}) *$

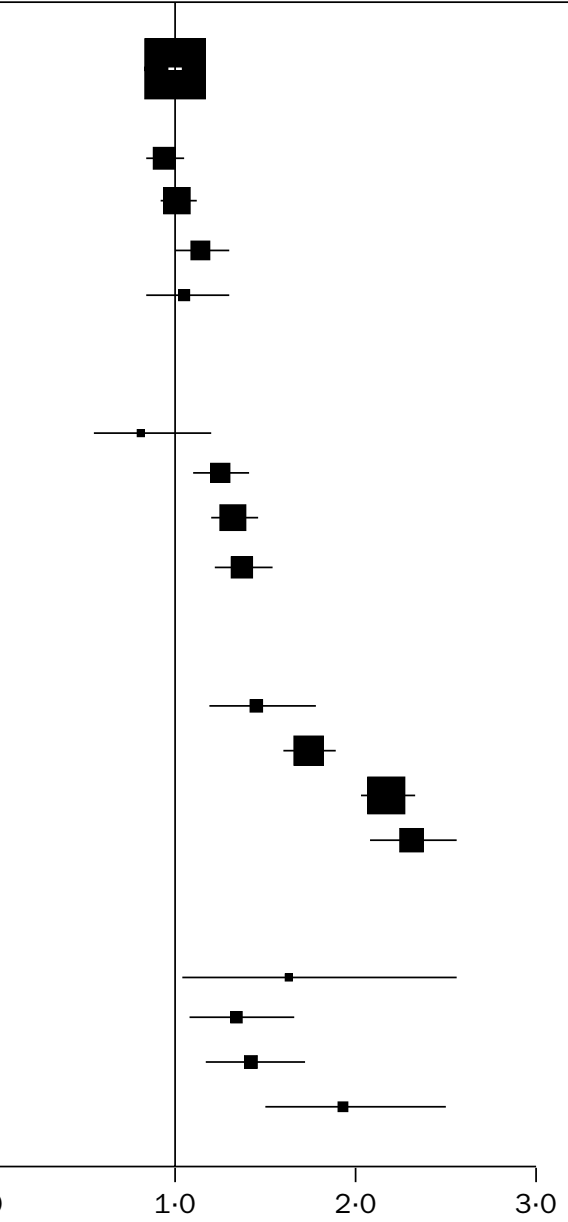

Figure 3: Relative risk of incident invasive breast cancer in relation to recency, total duration of use, and type of HRT used at baseline

$\mathrm{FCl}=$ floated $\mathrm{Cl}$ *Relative to never users, stratified by age, time since menopause, parity and age at first birth, family history of breast cancer, body-mass index, region, and deprivation index.

only HRT; $1.04(0.94-1 \cdot 16)$ for past users of oestrogenprogestagen HRT; and $1.08(0 \cdot 82-1 \cdot 42)$ for past users of tibolone.

Overall, the relative risk of breast cancer in current users at baseline increased with increasing total duration of use of HRT. Figure 3 shows results by total duration of use of HRT of less than 1 year, 1-4,5-9, and 10 or more years for women who at baseline were past or current users of oestrogen only, combined, and other or unknown HRT types. For current users of oestrogen only and oestrogenprogestagen combinations the relative risk of breast cancer was significantly raised in each duration category, except for users of oestrogen-only preparations with a total duration of use of less than 1 year at baseline. The relative risks associated with less than 5 and 5 or more years total duration of use at baseline were $1.21(1 \cdot 07-1 \cdot 37, p=0 \cdot 003)$ and $1.34 \quad(1.23-1.40 \quad \mathrm{p}<0.0001)$, respectively, for oestrogen-only HRT; and corresponding values were: $1 \cdot 70$ $(1.56-1 \cdot 85, \mathrm{p}<0.0001)$ and $2 \cdot 21(2.06-2 \cdot 37, \mathrm{p}<0.0001)$ for oestrogen-progestagen combinations; 1.32 (1.04-1.69, $\mathrm{p}=0.03)$ and $1.57(1.30-1.90, \mathrm{p}<0.0001)$ for tibolone; and $1.35(0.98-1.85, \mathrm{p}=0.06)$ and $1.54(1.16-2.04, \mathrm{p}=0.003)$ for other and unknown types of HRT. There was no raised risk of breast cancer among past users according to their previous total duration of use of HRT (figure 3).
Figure 4 shows the relative risk of breast cancer in current users of oestrogen-only preparations compared with never users of HRT, according to the specific hormonal constituent of the preparation used, its dose, and formulation. The relative risk of breast cancer was significantly raised, separately, for users of preparations containing equine oestrogen $(1.29[1 \cdot 16-1 \cdot 43], p<0.0001)$ and oestradiol $(1.24[1 \cdot 12-1 \cdot 37], \mathrm{p}<0 \cdot 0001)$, with no significant variation in the risk between users of each preparation $(p=0 \cdot 6)$ or according to their doses $(p=0.4$ for equine oestrogen; and $p=0.8$ for oestradiol). Similarly, the relative risk of breast cancer was significantly raised separately for users of oral, transdermal, and implanted formulations $\quad(1.32 \quad[1.21-1.45], \quad \mathrm{p}<0.0001 ; 1.24$ $[1 \cdot 11-1 \cdot 39], \mathrm{p}<0 \cdot 0001$; and $1.65[1 \cdot 26-2 \cdot 16], \mathrm{p}<0.0001$, respectively), with no significant variation in the risk between the formulations $(\mathrm{p}=0 \cdot 2)$.

Figure 5 shows the relative risk of breast cancer in current users of oestrogen-progestagen combinations compared with never users of HRT, according to the specific progestagen used at baseline and whether the progestagen was administered sequentially or continuously. To keep confounding between duration of use of HRT and use of specific preparations to a minimum, results are shown separately for total durations 
Oestrogen-only HRT by: constituent, dose, and formulation

rormulation

Cases/population

$991 / 115383$

$1 \cdot 30(1 \cdot 21-1 \cdot 40)$

\section{By constituent and dose}

$$
\begin{aligned}
& \text { All equine oestrogen } \\
& \leqslant 0.625 \mathrm{mg} \text { equine oestrogen } \\
& >0.625 \mathrm{mg} \text { equine oestrogen } \\
& \text { All ethinyloestradiol } \\
& \leqslant 1 \mathrm{mg} \text { ethinyloestradiol } \\
& >1 \mathrm{mg} \text { ethinyloestradiol }
\end{aligned}
$$

$426 / 48386$
$288 / 33039$
$135 / 15181$
$454 / 56322$
$367 / 44898$
$47 / 6455$

$1.29(1.16-1 \cdot 43)$
$1.25(1.11-1 \cdot 41)$
$1.36(1.14-1 \cdot 61)$
$1.24(1.12-1 \cdot 37)$
$1.25(1.12-1 \cdot 40)$
$1.19(0.89-1.58)$

\section{By formulation}

$\begin{array}{lcc}\text { Oral } & 606 / 68351 & 1 \cdot 32(1 \cdot 21-1 \cdot 45) \\ \text { Transdermal } & 324 / 40015 & 1 \cdot 24(1 \cdot 11-1 \cdot 39) \\ \text { Implanted } & 54 / 5272 & 1.65(1 \cdot 26-2 \cdot 16)\end{array}$

Relative risk (95\% CI) $\dagger$



Figure 4: Relative risk of incident invasive breast cancer by constituent, dose, and formulation of oestrogen only HRT preparation used at baseline*

*Dotted line represents overall relative risk for current users of oestrogen-only preparations compared with never users at baseline. Full information on specific constituents and their formulation was not available for some women. †Relative to never users, stratified by age, time since menopause, parity and age at first birth, family history of breast cancer, body-mass index, region, and deprivation index.

of use of HRT of less than 5 years and 5 years or more. In these two categories of use, the relative risk of breast cancer was significantly increased, separately, for users of preparations containing medroxyprogesterone acetate, norethisterone and norgestrel, and for users of sequential and continuous regimens. However, the relative risk of breast cancer showed little consistent variation according to the progestagen constituent or whether sequential or continuous regimens were used. The doses of each specific progestagen do not vary between the various preparations in such a way that would permit valid comparisons to be made. The relative risks of breast cancer for users of combined equine oestrogen and medroxyprogesterone acetate, the specific HRT combination used in the Women's Health Initiative trial, ${ }^{2,3}$ were $1.62(1 \cdot 34-1 \cdot 96$, $\mathrm{p}<0.0001)$ and $2.42(2.08-2 \cdot 81, \mathrm{p}<0.0001)$ for total duration of use of $<5$ and $\geqslant 5$ years, respectively.

\begin{tabular}{|c|c|c|}
\hline $\begin{array}{l}\text { Oestrogen-progestagen } \\
\text { HRT by: constituents } \\
\text { and regimen }\end{array}$ & Cases/populati & $\begin{array}{l}\text { Duration of use }<5 \\
\text { ion Rel }\end{array}$ \\
\hline $\begin{array}{l}\text { All oestrogen-progestagen } \\
\text { combinations }\end{array}$ & $679 / 59011$ & $1.70(1.56-1.86)$ \\
\hline \multicolumn{3}{|l|}{ By progestagen constituent } \\
\hline Medroxyprogesterone acetate & $117 / 11280$ & $1.60(1.33-1.93)$ \\
\hline Norethisterone & $253 / 24667$ & $1.53(1.35-1 \cdot 75)$ \\
\hline Norgestrel/levonorgestrel & $290 / 20952$ & $1.97(1 \cdot 74-2 \cdot 33)$ \\
\hline
\end{tabular}

The results in figures $2,3,4$, and 5 classify current users of HRT according to the type of preparation reported to have been used at baseline. In the study population as a whole, about two-thirds of the current users had used one proprietary preparation only (in that $66 \%$ of current users
By type of regimen

Sequential

Continuous
403/33 $124 \quad 1.77(1.59-1.97)$

$$
243 / 23708 \quad 1.57(1.37-1.79)
$$

Relative risk $(95 \% \mathrm{CI})$ * Cases/population

Duration of use $\geqslant 5$ years

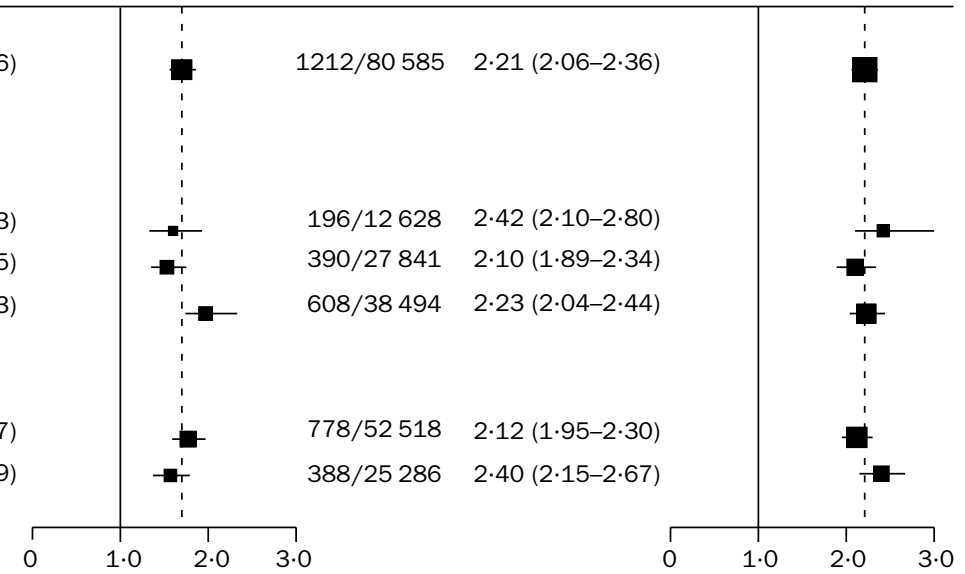

Figure 5: Relative risk of incident invasive breast cancer by constituent and regimen of oestrogen-progestagen combination HRT used at baseline*

*Dotted line represents overall relative risk for current users of oestrogen-progestagen preparations compared with never users at baseline. Full information on specific constituents and their formulation was not available for some women. †Relative to never users, stratified by age, time since menopause, parity and age at first birth, family history of breast cancer, body-mass index, region, and deprivation index. 


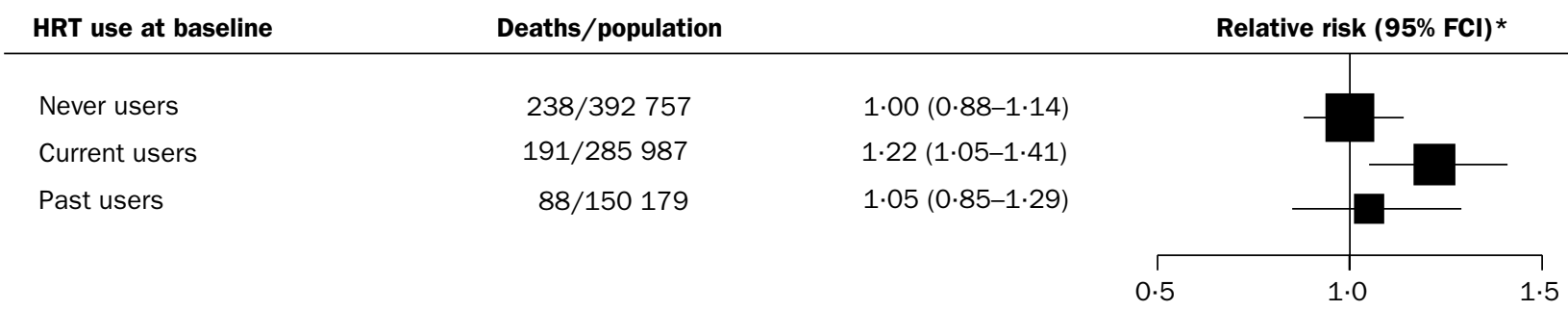

Figure 6: Relative risk of fatal breast cancer in relation to use of HRT at baseline

$\mathrm{FCl}=$ floated $\mathrm{Cl}$. *Relative to never users, stratified by age, time since menopause, parity and age at first birth, family history of breast cancer, body-mass index, region, and deprivation index.

reported using the most recent preparation for the same duration as their total duration of use of HRT), and the large majority of current users had used the most recent proprietary preparation for the longest period of time (87\% had used the most recent proprietary preparation for at least half their total duration of use of HRT). Furthermore, our validation studies have shown $97 \%$ agreement between self-reported data and family-physician records when specific proprietary preparations as classified as oestrogen only, oestrogen-progestagen, or another type of HRT. ${ }^{14}$ Since oestrogen-only preparations are used almost entirely by women without a uterus, and the converse is true for oestrogen-progestagen combinations, ${ }^{13}$ few women switch from using one of these types of HRT to the other.

Some current users of tibolone at baseline may have used other HRT preparations previously, and to isolate the effects of tibolone alone, analyses were restricted to women whose reported duration of use of tibolone was the same as their reported total duration of any type of HRT. Among such women, who were likely to have used tibolone exclusively, the relative risk of breast cancer in current users was $1.48(1 \cdot 20-1 \cdot 83, \mathrm{p}<0 \cdot 0001)$, based on 88 incident breast cancers, similar to the result for all current users of tibolone $(1.45[1.25-1 \cdot 68], p<0.0001$ figure 2). Current users of tibolone at baseline did not differ substantially from other current users of HRT for known risk factors for breast cancer $(8.0$ vs $8.2 \%$ had a family history of breast cancer; 10.7 vs $10.2 \%$ were nulliparous; $7 \cdot 7$ vs $7 \cdot 5 \%$ had their first birth after age 30 years; 50.5 vs $47.3 \%$ had a body-mass index of $25 \mathrm{~kg} / \mathrm{m}^{2}$ or more; $12 \cdot 3$ vs $13.3 \%$ had previous benign breast disease; and $29 \cdot 1$ vs $26.0 \%$ drank $10 \mathrm{~g}$ or more alcohol daily). Additional adjustment for those of the above factors which were not already included in the analysis model did not alter the estimates of relative risk of breast cancer associated with current use of tibolone.

Sensitivity analyses were done on the overall results for current and past users to assess the effect of restricting analyses further to include only women with a natural menopause and bilateral oophorectomy, who had begun use of HRT after their menopause. The relative risk, based on 4750 women with incident invasive breast cancer, compared with never users was $1.67(1.59-1.76$, $\mathrm{p}<0 \cdot 0001)$ for current users and $1.00(0.93-1 \cdot 08, \mathrm{p}=1 \cdot 0)$ for past users, which is similar to the results shown in figure 1 . In addition, to investigate possible confounding by other factors, results for current and past users and type of current HRT were adjusted in turn by age at menarche, alcohol consumption, past use of oral contraceptives, and past health. Adjustment by each factor altered the relative risks only at the second decimal place, if at all. Results in figures 1 and 2 were also examined separately by age, family history of breast cancer, body-mass index, and ever-use of oral contraceptives. The only factor that seemed to modify the relative risk estimates materially was body-mass index.
Among women with a body-mass index less than $25 \mathrm{~kg} / \mathrm{m}^{2}$ and $25 \mathrm{~kg} / \mathrm{m}^{2}$ or more, the respective relative risks of breast cancer were: $1.97(1.82-2 \cdot 14, \mathrm{p}<0.0001)$ and 1.46 $(1 \cdot 36-1 \cdot 58, \mathrm{p}<0.0001)$ for all current users of HRT; 1.53 $(1.36-1 \cdot 71, \mathrm{p}<0.0001)$ and $1.17(1.05-1.29, \mathrm{p}<0.003)$ for current users of oestrogen-only HRT; and 2.31 $(2 \cdot 12-2 \cdot 53, \mathrm{p}<0.0001)$ and $1.78(1.64-1.94, \mathrm{p}<0.0001)$ for current users of oestrogen-progestagen HRT (heterogeneity $\mathrm{p}<0.001$ for each comparison).

With $4 \cdot 1$ years of follow-up for mortality, the number of deaths from breast cancer in women without a history of cancer at recruitment is still relatively small -517 women in total died. Overall, the relative risk of death from breast cancer was raised in women who were current users of HRT at recruitment $(1 \cdot 22[1 \cdot 00-1 \cdot 48], \mathrm{p}=0 \cdot 05)$, but not in past users $(1.05[0 \cdot 82-1 \cdot 34, \mathrm{p}=0 \cdot 07])$, compared with never users (figure 6). Insufficient data are available to compare reliably deaths from breast cancer in users of oestrogen-only and oestrogen-progestagen preparations, or to investigate the relation between mortality and duration of use of HRT.

Among women from developed countries who never use HRT, the incidence of invasive breast cancer is estimated to be typically 32 in every 1000 between the ages of 50 and 65 years (table 2). ${ }^{1,18}$ The cumulative incidence of breast cancer per 1000 women associated with different patterns of use of HRT was calculated by applying the relative risk estimates from figure 3 to the estimated incidence rates in never users of HRT (table 2). 5 years' use of HRT, beginning at age 50 years, is estimated to result in 1.5 (95\% CI 0-3) additional breast cancers by age 65 years among 1000 users of oestrogen-only preparations, and six (5-7) additional cancers among 1000 users of oestrogenprogestagen combinations. 10 years' use is estimated to result in five (3-7) additional cancers in 1000 users of oestrogen-only preparations and 19 (18-20) additional cancers in 1000 users of combined HRT.

The main reason that women are prescribed combined rather than oestrogen-only HRT is because of the known

\begin{tabular}{|c|c|c|c|c|c|}
\hline & \multicolumn{5}{|c|}{ Estimated cumulative incidence of breast cancer } \\
\hline & \multirow[t]{2}{*}{$\begin{array}{l}\text { Never } \\
\text { users of } \\
\text { HRT }\end{array}$} & \multicolumn{2}{|c|}{$\begin{array}{l}\text { Duration use of } \\
\text { oestrogen only }\end{array}$} & \multicolumn{2}{|c|}{$\begin{array}{l}\text { Duration use of } \\
\text { oestrogen- } \\
\text { progestagen }\end{array}$} \\
\hline & & 5 years & 10 years & 5 years & 10 years \\
\hline \multicolumn{6}{|l|}{ Up to age (years) } \\
\hline 50 & 18 & 18 & 18 & 18 & 18 \\
\hline 55 & 27 & 28.5 & 29 & 34 & 34 \\
\hline 60 & 38 & $39 \cdot 5$ & 43 & 44 & 57 \\
\hline 65 & 50 & $51 \cdot 5$ & 55 & 56 & 69 \\
\hline $\begin{array}{l}\text { Excess cumulative } \\
\text { incidence per } \\
1000 \mathrm{HRT} \text { users } \\
(95 \% \mathrm{Cl})\end{array}$ & 0 & $\begin{array}{l}1 \cdot 5 \\
(0-3)\end{array}$ & $\begin{array}{l}5 \\
(3-7)\end{array}$ & $\begin{array}{l}6 \\
(5-7)\end{array}$ & $\begin{array}{l}19 \\
(18-20)\end{array}$ \\
\hline
\end{tabular}

Table 2: Cumulative and excess incidence of invasive breast cancer in $\mathbf{1 0 0 0}$ women who had never used and ever used HRT, based on incidence rates typical of developed countries 


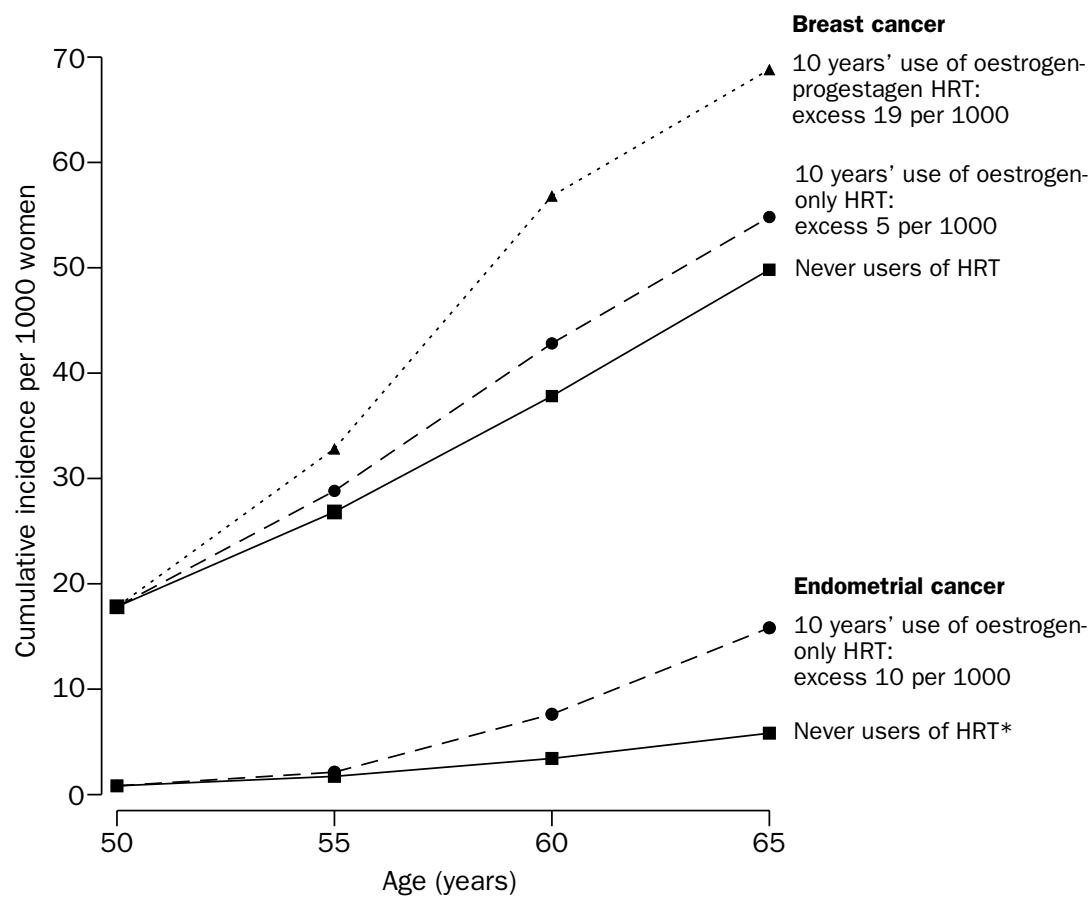

Figure 7: Estimated cumulative incidence of breast and endometrial cancer per 1000 women in developed countries who never used HRT and who used HRT for 10 years, beginning at age $\mathbf{5 0}$ years

*10 years' use of oestrogen-progestagen HRT estimated to result in little change in culmulative incidence of endometrial cancer.

increased risk of endometrial cancer associated with the use of oestrogen-only preparations. ${ }^{5,21-23}$ Among women in developed countries who do not use HRT, about five in every 1000 are diagnosed with endometrial cancer between ages 50 and 64 years. ${ }^{18}$ Calculations, similar in principle to those used to estimate the cumulative incidence of breast cancer, were done for endometrial cancer with estimates of relative risk from randomised trials ${ }^{2,4}$ and observational studies. ${ }^{21-23}$ Use of oestrogen-only preparations is estimated to result in an additional four endometrial cancers per 1000 for 5 years' use; and an additional ten per 1000 for 10 years' use; whereas use of combined oestrogenprogestagen HRT is estimated to result in little or no change in the cumulative incidence of endometrial cancer. (The limited available evidence suggests that use of sequential combined HRT might slightly increase the risk of endometrial cancer, ${ }^{5,21-23}$ and that use of continuous combined HRT might slightly lower the risk, ${ }^{2,22}$ but that 10 years' use of oestrogen-progestagen preparations is unlikely to increase or decrease the cumulative incidence by more than about two per 1000 users.)

Figure 7 shows the estimated cumulative incidence of breast and endometrial cancer in 1000 women from developed countries between the ages of 50 and 65 years: who never used HRT; who used oestrogen-only HRT for 10 years; and who used oestrogen-progestagen HRT for 10 years. Breast cancer is much more common than endometrial cancer, and 10 years' use of either type of HRT results in an increase in the incidence of one or other of the cancers. However, for oestrogen-only HRT the excess incidence is due largely to endometrial cancer, whereas for combined HRT the excess is exclusively made up of breast cancers.

Over the past decade about 15000 invasive breast cancers have been diagnosed each year in women aged 50-64 years in the UK. ${ }^{20}$ If it is assumed that the relative risk estimates in this study associated with use of different types of HRT are unbiased and that in the general population of the UK an average of $25 \%$ of women aged 50-64 years were current users of HRT during the past decade, , $^{5,14}$ about 20000 extra breast cancers are estimated to have occurred over the past 10 years among women aged 50-64 as a result of their use of HRT. Moreover, if the distribution of use of specific types of HRT is similar to that observed in this study, 15000 of these 20000 additional breast cancers are due to the use of oestrogen-progestagen HRT. The number of extra deaths from breast cancer attributable to HRT cannot yet be estimated.

\section{Discussion}

The results of this study confirm previous findings that current and recent use of HRT increases the risk of breast cancer, ${ }^{1-10}$ but also provides new and reliable information about the effects of various patterns of use. The Million Women Study was set up to examine the effect of HRT on breast cancer incidence and mortality. Study participants were recruited at the time of their triennial invitation for routine mammography by the NHSBSP. The programme provides a routine screening service only; women cannot be referred or selfrefer for mammography at times outside the 3-year screening cycle. The NHSBSP does not provide a diagnostic mammographic service, and women with breast lumps and other symptoms have mammograms and other investigations done outside the programme. Around $75 \%$ of UK women invited by the NHSBSP attend for routine mammography, and $71 \%$ of the women screened at participating centres took part in the Million Women Study, amounting to $53 \%$ participation in the general population. Study participants were similar to all women screened, who themselves are slightly more likely to use HRT and to come from less-deprived areas than women who do not attend the NHSBSP for routine mammography. ${ }^{12}$ Although the study cohort contains a slightly greater proportion of HRT users than in the general population, this difference would not bias internal comparisons within the cohort of breast cancer risk according to use of HRT.

All study participants had routine mammography soon after they completed their baseline questionnaires. Thus any biases resulting from differential reporting of use of HRT according to the outcome of interest-ie, breast cancer-or differential screening for the exposure of interest - ie, use of HRT - were virtually eliminated. Few women who attend the NHSBSP have mammography done privately at other times, and most breast cancers diagnosed among study participants in the interval between their triennial routine NHSBSP screens are symptomatic interval cancers. Use of HRT reduces the sensitivity of mammography, thus increasing the probability that a breast cancer is diagnosed as an interval rather than a screendetected cancer. ${ }^{24}$ Therefore, to investigate how HRT affects the underlying risk of breast cancer, the overall incidence of breast cancer (taking screen-detected and interval breast cancers together) must be studied, as we have done. All women were flagged on the NHS Central 
Registers, with details of each registered incident cancer and death being automatically coded and reported to study investigators. Therefore, the recording of incident and fatal breast cancer is unbiased for use of HRT and there should be little, if any, differential loss to follow-up.

Randomised trials have reported significantly increased risks of breast cancer in HRT users. ${ }^{2,3}$ In non-randomised studies, such as this one, the relation between breast cancer and HRT use can be confounded by women's menopausal status: for women of a given age, premenopausal and perimenopausal women are at greater risk of breast cancer and are less likley to use HRT than postmenopausal women, ${ }^{1}$ as was found here. To keep such confounding to a minimum we excluded premenopausal and perimenopausal women and women aged 50-52 years if they had had a hysterectomy or had begun using HRT before the menopause (since menopause can be masked by such interventions). Sensitivity analyses, done to assess the extent of such potential confounding, showed that when stricter exclusion criteria were applied, the point estimates for the relative risk of breast cancer in current and past users of HRT varied by less than $1 \%$.

Analyses were routinely stratified by age, time since menopause, parity and age at first birth, family history of breast cancer, body-mass index, region of residence, and deprivation index, thus keeping to a minimum confounding by these factors. Examination of potential confounding by alcohol consumption, previous use of oral contraceptives, age at menarche and past health, did not alter the relative risk estimates for current and past users compared with never users. The only factor that modified the relative risk estimates was body-mass index, with the relative risk estimates being larger among the thinner women - ie, those with a lower rather than a higher index.

Misclassification of women's use of HRT should not affect the main conclusions. Self-reported information on use of HRT at baseline was used to define current, past, and never users, and users were further classified according to the reported specific proprietary preparation used most recently. Validation studies within the study population showed $96 \%$ agreement between self-reported data at baseline and family-physician prescriptions for current use of HRT. ${ }^{14}$ Moreover, among current users, there was $97 \%$ agreement as to whether oestrogen-only, oestrogen-progestagen combination, or another type of HRT was being used, and $90 \%$ agreement for the specific proprietary preparation used and its dose. ${ }^{14}$ An estimated two-thirds of current users used one proprietary HRT preparation exclusively; and five-sixths of the current users had used their current HRT for at least half their total period of use of HRT. The incident breast cancers were diagnosed on average 1.2 years after recruitment, and some women would have changed their use of HRT during that period. Results from a survey of a random sample of 12221 study participants, done an average of $2 \cdot 8$ years after the recording of baseline information, showed that $78 \%$ of the current users at baseline were still using HRT, that $81 \%$ of past users were still past users, and that $89 \%$ of the never users were still never users. Among current users at baseline, the total duration of use of HRT at the time of diagnosis of breast cancer would be slightly longer than that recorded at baseline. However, any resultant underestimation of total duration of use of HRT would be counteracted, to some extent, by the fact that during follow-up some current users would have become past users and that some never users would have become current users.

Overall, these results confirm previous findings that current and recent users of HRT are at an increased risk of invasive breast cancer, and that the relative risk of breast cancer in current users increases with increasing duration of use of HRT. ${ }^{1-4}$ The estimated absolute increases in the incidence of breast cancer among women using oestrogen-only preparations are remarkably similar to estimates derived from a collaborative reanalysis of most of the relevant worldwide data in 1997, $80 \%$ of whom used oestrogen-only HRT. ${ }^{1}$ (The respective estimates per 1000 cases are 1.5 [0-3] and two [1-3] for 5 years' use, and five [3-7] and six [3-9] for 10 years' use.) Few estimates of the absolute increase in breast cancer incidence are available for users of oestrogenprogestagen HRT. The Women's Health Initiative trial found an increased incidence of breast cancer in women who complied with treament, ${ }^{3}$ of about six per 1000 women after 5 years' use, and 18 per 1000 after 7 years' use of oestrogen-progestagen HRT, similar to results from the Million Women Study, based on substantially larger numbers, of an increase in the cumulative incidence of six (5-7) per 1000 for 5 years' use and 19 (18-20) per 1000 for 10 years' use of oestrogenprogestagen HRT. Hence, for these durations oestrogenprogestagen combinations leads to about a four-fold greater increase in breast cancer incidence than does use of oestrogen-only preparations.

Other than the substantial difference between the effects of oestrogen-only and oestrogen-progestagen combinations, these results suggest no large variations between the effects of specific oestrogens (equine oestrogen and oestradiol) or between specific progestagens (medroxyprogesterone acetate, norgestrel, and norethisterone). They also suggest that results on the risk of breast cancer for the specific constituents used in the Women's Health Initiative trial ${ }^{3}$ do not differ materially from the results for other oestrogenprogestagen combinations. Nor does the available evidence suggest large differences between the effects of progestagens given sequentially or continuously on breast cancer, although if many women have switched use, this would dilute any real differences.

A significant excess of breast cancer was found for current use of tibolone. This increase is not due to confounding by known risk factors for breast cancer, such as family history of breast cancer, obesity, or late childbearing. Implanted and transdermal preparations of oestrogen-only HRT also led to a significant excess of breast cancer. There was, however, no significant difference between the effects of oral, transdermal, or implanted formulations. The implications of these findings need further investigation.

Current users of HRT at baseline had significantly increased mortality from breast cancer, although the relative risk estimate was of borderline significance and was not as large as for incident disease. The results for fatal disease are based on 517 deaths in women who had no history of breast cancer at recruitment. Had we included women with a history of breast cancer at baseline (among whom a further 485 deaths from breast cancer were reported, but only $3 \%$ of whom were using HRT at recruitment) we would have concluded, falsely, that current users of HRT had a substantially lower death rate from breast cancer than never users. Studies purporting to show that current users of HRT have lower death rates from breast cancer than non-users have generally been unable to account adequately for this fundamental source of bias. ${ }^{4}$ Results from the Women's Health Initiative trial show that breast cancers diagnosed in women allocated to HRT had a significantly larger size than the cancers in non-users of $\mathrm{HRT}^{3}{ }^{3}$ further 
challenging the validity of claims that use of HRT decreases mortality from breast cancer. Longer follow-up of this and other cohorts and further information on the effects of different patterns of use of HRT on mortality from breast cancer are needed.

The results from the Million Women Study suggest little or no overall increase in the relative risk of breast cancer in past users of HRT. No residual increase in the risk of breast cancer was seen separately for past users of oestrogen only, oestrogen-progestagen combinations, or tibolone. These findings are broadly in line with results from previous studies that had suggested that the effects of current use of HRT on the risk of breast cancer wore off largely, if not wholly, within 5 years of ceasing use of HRT. ${ }^{1}$

Use of HRT by UK women aged $50-64$ years in the past decade is estimated to have resulted in an extra 20000 incident breast cancers, combined oestrogenprogestagen HRT accounting for 15000 of these additional cancers. The main reason that women are prescribed combined rather than oestrogen-only, HRT is because of the increased risk of endometrial cancer associated with use of oestrogen-only preparations. However, if the additional breast and endometrial cancers associated with each type of HRT are added together, there seems to be little advantage to using oestrogenprogestagen in preference to oestrogen-only HRT for women who still have a uterus. Use of either type of HRT is estimated to result in five to six extra cancers per 1000 women with 5 years' use and 15-19 extra cancers per 1000 with 10 years' use of HRT. The extra cancers are predominantly of the endometrium for users of oestrogenonly preparations, whereas they are exclusively breast cancer for users of oestrogen-progestagen HRT. Reliable estimates of the extra deaths from breast cancer attributable to use of HRT cannot be made at present.

Conflict of interest statement

None declared.

Analysis and writing committee

Emily Banks, Valerie Beral, Diana Bull, Gillian Reeves.

\section{Steering committee}

Joan Austoker, Emily Banks, Valerie Beral, Ruth English, Julietta Patnick, Richard Peto, Gillian Reeves, Martin Vessey (Chair), Matthew Wallis.

\section{Million Women Study coordinating centre staff}

Simon Abbott, Emma Bailey, Krys Baker, Angela Balkwill, Emily Banks, Isobel Barnes, Valerie Beral, Judith Black, Anna Brown, Diana Bull, Becky Cameron, Karen Canfell, Andrea Cliff, Barbara Crossley, Elisabeth Couto, Stephen Davies, Dave Ewart, Sarah Ewart,

Debbie Ford, Laura Gerrard, Adrian Goodill, Jane Green, Winifred Gray, Elizabeth Hilton, Ann Hogg, Joy Hooley, Anna Hurst, Sau Wan Kan, Carol Keene, Nicky Langston, Gillian Reeves, Andrew Roddam, Phil Saunders, Emma Sherman, Moya Simmonds, Elizabeth Spencer, Helena Strange, Alison Timadjer.

\section{NHS Breast Screening Centres participating in the Million} Women Study

Avon, Aylesbury, Barnsley, Basingstoke, Bedfordshire and Hertfordshire, Cambridge and Huntingdon, Chelmsford and Colchester, Chester, Cornwall, Crewe, Cumbria, Doncaster, Dorset, East Berkshire, East Cheshire, East Devon, East of Scotland, East Suffolk, East Sussex, Gateshead, Gloucestershire, Great Yarmouth, Hereford and Worcester, Kent (Canterbury, Gillingham, Maidstone), Kings Lynn, Leicestershire, Liverpool, Manchester, Milton Keynes, Newcastle, North Birmingham, North East Scotland, North Lancashire, North Middlesex,

North Nottingham, North of Scotland, North Tees, North Yorkshire, Nottingham, Oxford, Portsmouth, Rotherham, Sheffield, Shropshire, Somerset, South Birmingham, South East Scotland, South East Staffordshire, South Derbyshire, South Essex,

South Lancashire, South West Scotland, Surrey,

Warrington Halton St Helens \& Knowsley,

Warwickshire Solihull and Coventry, West Berkshire, West Devon, West London, West Suffolk, West Sussex, Wiltshire, Winchester, Wirral and Wycombe.
Acknowledgments

We thank each woman who participated in the Million Women Study; collaborators from the NHS Breast Screening Centres; members of the study coordinating centre; and the study steering committee. This research was funded by Cancer Research UK, the NHS Breast Screening Programme, and the Medical Research Council.

\section{References}

1 Collaborative Group on Hormonal Factors in Breast Cancer. Breast cancer and hormone replacement therapy: collaborative reanalysis of data from 51 epidemiological studies of 52705 women with breast cancer and 108411 women without breast cancer. Lancet 1997; 350: 1047-59.

2 Writing Group for the Women's Health Initiative Investigators. Risks and benefits of estrogen plus progestin in healthy postmenopausal women: principal results from the Women's Health Initiative randomized controlled trial. $f A M A$ 2002; 288: 321-33.

3 Chlebowski RT, Hendrix SL, Langer RD, et al, for the WHI Investigators. Influence of estrogen plus progestin on breast cancer and mammography in healthy postmenopausal women: the Women's Health Initiative randomised trial. $f A M A$ 2003; 289: 3243-53.

4 Beral V, Banks E, Reeves G. Evidence from randomised trials on the long-term effects of hormone replacement therapy. Lancet 2002; 360: $942-44$.

5 Beral V, Banks E, Reeves G, Appleby P. Use of HRT and the subsequent risk of cancer. F Epidemiol Biostat 1999; 4: 191-215.

6 Berquist L, Adami H-O, Persson I, Hoover R, Schairer C. The risk of breast cancer after estrogen and estrogen-progestin replacement. N Engl f Med 1989; 321: 293-97.

7 Magnusson C, Baron JA, Correia N, Bergstrom R, Adami H-O, Persson I. Breast cancer risk following long-term oestrogen and oestrogen-progestin-replacement therapy. Int $\mathcal{F}$ Cancer 1999; 81: 339-44.

8 Schairer C, Lubin J, Troisi R, Sturgeon S, Brinton L, Hoover R. Menopausal estrogen and estrogen-progestin replacement therapy and breast cancer risk. FAMA 2000; 283: 485-91.

9 Ross RK, Paganini-Hill A, Wan PC, Pike MC. Effect of Hormone replacement therapy on breast cancer risk: estrogen versus estrogen plus progestin. I Natl Cancer Inst 2000; 92: 328-32.

$10 \mathrm{Li}$ CI, Malone KE, Porter PL, Weiss NS, et al. Relationship between long durations and different regimens of hormone therapy and risk of breast cancer. $7 A M A$ 2003; 289: 3254-63

11 The Million Women Study Collaborative Group. The Million Women Study: design and characteristics of the study population. Breast Cancer Res 1999; 1: 73-80.

12 Banks E, Beral V, Cameron R, et al. Comparison of various characteristics of women who do and do not attend for breast cancer screening. Breast Cancer Res 2001; 4: R1.1-1.6.

13 Million Women Study Collaborators. Patterns of use of hormone replacement therapy in one million women in Britain, 1996-2000. Brf Obst Gynaecol 2002; 109: 1319-30.

14 Banks E, Beral V, Cameron R, et al. Agreement between general practice prescription data and self-reported use of hormone replacement therapy and treatment for various illnesses. $\mathcal{F}$ Epidemiol Biostat 2001; 6: 357-63.

15 British Medical Association and Royal Pharmaceutical Society of Great Britain. British national formulary. London: BMJ Books, 1999.

16 International Statistical Classification of Diseases and Related Health Problems, 10th revision. Geneva: World Health Organization, 1992.

17 Easton DF, Peto J, Babiker AGAG. Floating absolute risk: an alternative to relative risk in survival and case-control analysis avoiding an arbitrary reference group. Stat Med 1991; 10: 1025-35.

18 Parkin DM, Whelan SL, Ferlay J, Teppo L, Thomas DB, eds. Cancer incidence in five continents, vol VIII. Lyon: International Agency for Research on Cancer Scientific Publications, 2002.

19 Key health statistics from general practice 1998: series MB6 (no 2). London: Office for National Statistics, 2000.

20 Cancer Research UK. Breast Cancer Factsheet, June 2003. http://www.cancerresearchuk.org/aboutcancer/statistics/statsmisc/pdfs/f actsheet_breast_jun2003.pdf (accessed July 10, 2003).

21 Pike MC, Peters RK, Cozen W, et al. Estrogen-progestin replacement therapy and endometrial cancer. F Natl Cancer Inst 1997; 89: 1110-16.

22 Weiderpass E, Adami H-O, Baron JA, et al. Risk of endometrial cancer following estrogen replacement with and without progestagins. 7 Natl Cancer Inst 1999; 91: 1131-37.

23 Newcomb PA, Trentham-Deitz A. Patterns of postmenopausal progestagen use with estrogen in relation to endometrial cancer (United States). Cancer Causes Control 2003; 14: 195-201.

24 Banks E. Hormone replacement therapy and the sensitivity and specificity of breast cancer screening: a review. F Med Screen 2001; 8: 29-34. 